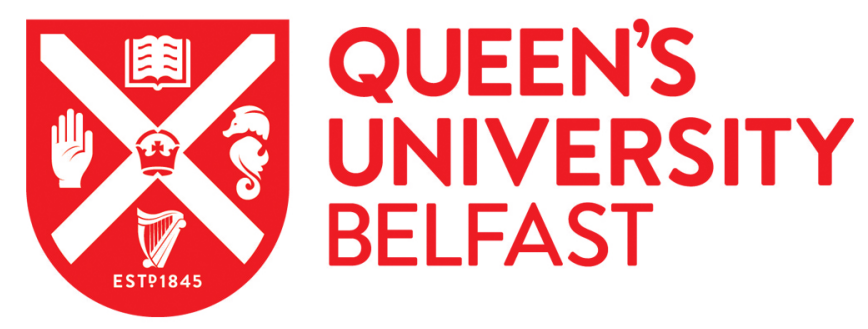

\title{
An international comparison of legal frameworks for supported and substitute decision-making in mental health services
}

\author{
Davidson, G., Brophy, L., Campbell, J., Farrell, S. J., Gooding, P., \& O'Brien, A-M. (2016). An international \\ comparison of legal frameworks for supported and substitute decision-making in mental health services. \\ International Journal of Law and Psychiatry, 44, 30-40. https://doi.org/10.1016/j.ijlp.2015.08.029
}

\section{Published in:}

International Journal of Law and Psychiatry

\section{Document Version:}

Peer reviewed version

Queen's University Belfast - Research Portal:

Link to publication record in Queen's University Belfast Research Portal

\author{
Publisher rights \\ (c) 2015 Elsevier. \\ This manuscript version is made available under the CC-BY-NC-ND 4.0 license (http://creativecommons.org/licenses/by-nc-nd/4.0/), which \\ permits distribution and reproduction for non-commercial purposes, provided the author and source are cited.
}

\section{General rights}

Copyright for the publications made accessible via the Queen's University Belfast Research Portal is retained by the author(s) and / or other copyright owners and it is a condition of accessing these publications that users recognise and abide by the legal requirements associated with these rights.

Take down policy

The Research Portal is Queen's institutional repository that provides access to Queen's research output. Every effort has been made to ensure that content in the Research Portal does not infringe any person's rights, or applicable UK laws. If you discover content in the Research Portal that you believe breaches copyright or violates any law, please contact openaccess@qub.ac.uk. 
Title: An international comparison of legal frameworks for supported and substitute decisionmaking in mental health services.

Authors: Gavin Davidson ${ }^{\mathrm{a}}$, Lisa Brophy ${ }^{\mathrm{b}}$, Jim Campbell ${ }^{\mathrm{c}}$, Susan J. Farrell ${ }^{\mathrm{d}}$, Piers Gooding ${ }^{\mathrm{e}}$, Ann-Marie O’Brien ${ }^{\mathrm{f}}$.

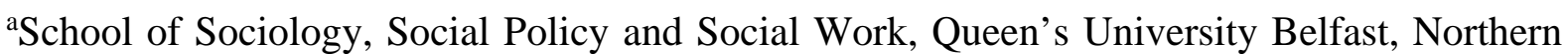
Ireland

${ }^{\mathrm{b}}$ Mind Australia and the School of Population and Global Health, University of Melbourne, Australia

${ }^{\mathrm{c}}$ Goldsmiths, University of London, England

${ }^{\mathrm{d}}$ Royal Ottawa Mental Health Centre and University of Ottawa, Canada

${ }^{\mathrm{e} C e n t r e ~ f o r ~ D i s a b i l i t y ~ L a w ~ a n d ~ P o l i c y, ~ N a t i o n a l ~ U n i v e r s i t y ~ o f ~ I r e l a n d, ~ G a l w a y ~}$

${ }^{\mathrm{f}}$ Royal Ottawa Mental Health Centre and Adjunct faculty, Carleton University

Corresponding author: Gavin Davidson, Senior Lecturer in Social Work, School of Sociology, Social Policy and Social Work, Queen’s University Belfast, Northern Ireland, BT7 1NN. Telephone: +44(0)2890973151. Email: g.davidson@qub.ac.uk

Accepted by the International Journal of Law and Psychiatry on 20/02/15 for publication in 2016 


\section{Abstract}

There have been important recent developments in law, research, policy and practice relating to supporting people with decision-making impairments, in particular when a person's wishes and preferences are unclear or inaccessible. A driver in this respect is the United Nations Convention on the Rights of Persons with Disabilities (CRPD); the implications of the CRPD for policy and professional practices are currently debated. This article reviews and compares four legal frameworks for supported and substitute decision-making for people whose decisionmaking ability is impaired. In particular, it explores how these frameworks may apply to people with mental health problems. The four jurisdictions are: Ontario, Canada; Victoria, Australia; England and Wales, United Kingdom (UK); and Northern Ireland, UK. Comparisons and contrasts are made in the key areas of: the legal framework for supported and substitute decision-making; the criteria for intervention; the assessment process; the safeguards; and issues in practice. Thus Ontario has developed a relatively comprehensive, progressive and influential legal framework over the past thirty years but there remain concerns about the standardisation of decision-making ability assessments and how the laws work together. In Australia, the Victorian Law Reform Commission (2012) has recommended that the six different types of substitute decision-making under the three laws in that jurisdiction, need to be simplified, and integrated into a spectrum that includes supported decision-making. In England and Wales the Mental Capacity Act 2005 has a complex interface with mental health law. In Northern Ireland it is proposed to introduce a new Mental Capacity (Health, Welfare and Finance) Bill that will provide a unified structure for all substitute decision-making. The discussion will consider the key strengths and limitations of the approaches in each jurisdiction and identify possible ways that further progress can be made in law, policy and practice. 
Keywords: mental health law; mental capacity law; guardianship; UNCRPD; supported decision-making; substitute decision-making.

\section{Introduction}

This article seeks to reflect on issues of law, research, policy and practice in the context of what is described in international disability law as supported and substitute decision-making. To do so it will compare developments across four chosen jurisdictions: Ontario, Canada; Victoria, Australia; England and Wales; and Northern Ireland. We are particularly interested in decision-making that may be impaired due to mental health problems, because, in many jurisdictions, substitute decision making laws based on decision making ability - in particular, guardianship and other mental capacity laws - have been developed in parallel to existing and separate mental health laws. In a number of situations this has created complex overlaps and some logical inconsistencies that discriminate against people with mental health problems. To deal with this Dawson and Szmukler (2006) and Szmukler, Daw and Callard (2014) have proposed that there should be a single or fused framework to facilitate interventions, based on a mental capacity approach, with appropriate safeguards for everyone.

Previous international comparisons of legal frameworks for decision-making have highlighted important commonalities and differences. Campbell, Brophy, Healy and O’Brien (2006) focused on the use of compulsory powers in the community and made the important point that for any legal framework to be successfully and ethically implemented, adequate services and support must be available. Fistein, Holland, Clare and Gunn (2009) compared 32 Commonwealth mental health laws and identified that only two of them, Scotland and South Africa, have included an ability-based capacity test for both hospitalisation and treatment. Gray, McSherry, O’ Reilly and Weller (2010) examined mental health laws across Australian 
and Canadian jurisdictions and concluded that mental health law in Australia has tended to have to have a stronger focus on treatment rather than a rights-based focus to be found in some Canadian laws. In the light of such comparisons, and a number of recent developments in policy and law, we later re-examine and compare some of these issues in the context of our chosen four jurisdictions.

Before doing so it is important to acknowledge some of the on-going debates that have been raised about supported and substitute decision-making, particularly with reference to the CRPD (Power, Lord \& DeFranco, 2013). The CRPD, and its associated jurisprudence (Committee on the Rights of Persons with Disabilities, 2014) have provoked discussion on a range of key questions about legal frameworks for supported and substitute decision-making:

(i) Should mental health problems be framed and regarded as a form of disability? Article 1 of the CRPD states that "Persons with disabilities include those who have long-term physical, mental, intellectual or sensory impairments which in interaction with various barriers may hinder their full and effective participation in society on an equal basis with others”. This would suggest that long-term impairments due to mental health problems should be regarded as a form of disability. Kelly (2014) points out that this definition is not presented as being comprehensive, it includes people with long-term impairments but does not exclude others. It is hard to justify why short-term and/or fluctuating disabling mental health problems would not also raise the same issues and require the same protections. Substitute decision-making under mental health law, usually in the form of compulsory intervention, has traditionally been based on the criteria of mental disorder and risk. 
(ii) Is any form of substitute decision making necessary? And can any form of substitute decision making be compatible with the CRPD?

Article 12 of the CRPD requires States to: "recognize that persons with disabilities enjoy legal capacity on an equal basis with others" (12.2); that States "take appropriate measures to provide access by persons with disabilities to the support they may require in exercising their legal capacity" (12.3); and States should "ensure that all measures that relate to the exercise of legal capacity provide for appropriate and effective safeguards” (12.4). There has been considerable argument about what 'exercising legal capacity on an equal basis with others' actually means. McSherry (2012) has asserted that legal capacity, as it is advanced in international human rights law, includes both a person's legal standing or status, and their legal agency or power to act. This notion of legal capacity is distinct from mental capacity, which refers to a designation of cognitive functioning. This suggests that even if a citizen is not able to make a specific decision, in other words they do not have the mental capacity to decide and cannot exercise their power to act, their legal rights should not be compromised, hence the need for 'appropriate and effective safeguards'. The terms 'supported decision-making' and 'substitute decision-making' are also contested, interpreted variously by commentators and governments. At issue is how states can adhere to the mandate of Article 12 to ensure that people with disabilities can be provided with 'support to exercise legal capacity' on an equal basis with others; this we argue below is a particularly challenging proposition in the context of mental health law and service provision. It would be concerning if this notion was to be interpreted as requiring the extreme libertarian or Szaszian (1961) position where compulsory intervention, based on impairment due to mental health problems, should not be allowed in any circumstances.

(iii) How can people with mental health problems be supported to make decisions? 
Although making every effort to support people to make their own decisions is already considered good practice, Article 12 of the CRPD now requires states to: "take appropriate measures to provide access by persons with disabilities to the support they may require in exercising their legal capacity” (12.3). This question raises a number of issues for practice, in particular the need for clarification between formal supports to ensure legal capacity and more general supports for decision making (Browning, Bigby \& Douglas, 2014). Then (2013) highlights remaining conceptual, legal and practical problems in defining and implementing supported decision-making. Reviews of the research evidence on what works in supporting people to make decisions suggest that, although there are some approaches that do appear to be effective for some people, further research is needed to develop effective, comprehensive supported decision making systems (Carney, 2014; Davidson et al, in press; Kohn, Blumenthal \& Campbell, 2012).

In addition to the impact of the CRPD on debates about reforming mental health law and policy, two other significant issues in the literature are relevant to this article - risk assessment and effectiveness. Large, Ryan, Singh, Paton and Nielssen (2011) have argued that risk assessment cannot sufficiently and accurately predict who is, or is not, going to harm themselves or others; the result is that a very high number of false positives are assumed (in other words people who are assessed as presenting a high risk who will not cause harm). Szmukler and Rose (2013) have further explored some of the unintended consequences of basing substitute decisionmaking on such an inaccurate process and highlighted its negative impact on trust in therapeutic relationships and in the consequent implications for social exclusion and discrimination.

The final development, which will only be considered briefly here, is the outcome of research into risk-based legal frameworks for involuntary treatment in community settings (often 
referred to as Community Treatment Orders (CTOs) or 'assisted outpatient treatment'). The most recent randomised controlled trial of CTOs (Burns et al., 2013), which compared brief to prolonged compulsion, mirrored findings from previous studies (Churchill, Owen, Singh \& Hotopf, 2007). The evidence indicates that assessment approaches focusing on the duality of mental disorder and risk, and subsequent restrictions on autonomy, do not appear to be an effective approach to reducing readmission rates in these contexts (Rugkåsa \& Dawson, 2013).

Given the developments in research and in international human rights law noted above we believe that it is timely to consider current legal frameworks for supported and substituted decision-making in the context of mental health law, policy and context, in particular which aspects may need to be reformed or replaced.

\section{Supported and substitute decision-making}

Before examining each chosen jurisdiction it is useful to consider the meaning of the terms 'supported decision-making' and 'substitute decision-making.' The term 'supported decisionmaking' is not defined in the CRPD, but some understanding can be found in Article 12(3), particularly the obligation it places on States to provide 'access by persons with disabilities to the support they may require in exercising their legal capacity’ on an equal basis with others. Hence, in international human rights law, 'supported decision-making' is one constitutive element of 'support to exercise legal capacity,' and refers to a person making a decision on his or her own behalf, with support in order to exercise his or her legal capacity (Browning, Bigby \& Douglas, 2014). Further elaboration is provided by the Office of the High Commissioner for Human Rights in its United Nations Handbook for Parliamentarians (2007), which states that: 
Supported decision-making can take many forms. Those assisting a person may communicate the individual's intentions to others or help him/her understand the choices at hand. They may help others to realize that a person with significant disabilities is also a person with a history, interests and aims in life, and is someone capable of exercising his/her legal capacity. (pp. 90-91).

Various definitions tend to focus on the straightforward proposition of assisting people who require support to make their own decisions. For example, the Victorian Law Reform Commission (2012, p.xviii), defines supported decision-making as: “An approach to decision making that involves providing a person with impaired decision making ability the support they need to make their own decision. It is often contrasted with substitute decision making, where a decision is made on behalf of a person who is unable to make that decision.”

The term 'substitute decision-making' is used in international disability rights law to refer to the appointment of someone to make decisions on behalf of a person deemed to lack the mental capacity required for a decision to be made (for example, regarding accommodation, healthcare, or financial decisions). The CRPD Committee (2014) define 'substituted decisionmaking regimes’ as follows:

Substitute decision-making regimes can take many different forms, including plenary guardianship, judicial interdiction and partial guardianship. However, these regimes have certain common characteristics: they can be defined as systems where (i) legal capacity is removed from a person, even if this is just in respect of a single decision; (ii) a substitute decision-maker can be appointed by someone other than the person concerned, and this can be done against his or her will or (iii) 
any decision made by a substitute decision-maker is based on what is believed to be in the objective "best interests" of the person concerned, as opposed to being based on the person's own will and preferences. (Paragraph 23)

As the CRPD Committee point out, the range of 'substituted decision-making in law' is difficult to generalise; it includes arrangements such as powers of attorney, court-appointed deputies, guardianship, wards of court and compulsory intervention under mental health law all of which differ considerably in their nature, and in the extent to which they intercede on a person’s legal capacity.

The distinction between supported and substituted decision-making is not always clear. For example, in some jurisdictions (such as Alberta, Saskatchewan and law proposed in the Republic of Ireland) there are co-decision-making arrangements which involve the courts appointing someone to assist the person to make decisions, but under these arrangements the person's autonomy is not viewed to be absolute and so these processes may be regarded as a more limited forms of substitute decision-making - at least, according to the definition of the CRPD Committee. Further, the CRPD Committee has interpreted Article 12 so that in 'hard cases', such as where a person is minimally communicative or is in a comatose state, decisionmaking by third parties might be guided by the 'best interpretation of the person's will and preferences' - not a 'best interests' standard. It could be argued that it is a semantic stretch to frame responses to these most difficult situations as supported decision making based only on the person's own will and preferences, this implies that there is a need for a new way of framing these situations. Again, these terms seem to be used variously in different contexts, and the translation of these concepts into law and policy at the domestic level is very much a work in progress. 
No jurisdiction appears likely in the near future to eliminate substituted decision-making according to the standard set by the CRPD Committee. As shall be discussed below, domestic laws which encourage or require supported decision-making can be viewed in terms of spectrum across in which substitute decision-making is also involved. This ranges from: autonomous decision-making at one end, supported decision-making as a mid-way point, and substituted decision-making in exceptional cases, at the other end of the spectrum. This pragmatic response does not meet the CRPD Committee's directive that States replace substitute decision-making regimes by supported decision-making. The CRPD Committee (2014) have stated, "the development of supported decision-making systems in parallel with the maintenance of substitute decision-making regimes is not sufficient to comply with article 12 of the Convention.” (p.6).

In considering how a law and policy framework might support people to exercise their legal capacity on an equal basis with others, it is important to note the wide scope of reform of law that would be necessary to remove use of mental capacity assessments and 'best interests' standards that guide ‘coercive care', to use McSherry and Freckleton's (2013) term. In order to reform laws to meet the mandate of Article 12 of the CRPD a range of other multiple areas of law, including criminal law, contract law, and health law would have to take place. Hence, it is perhaps salient to consider Carney’s (2012) warning that a 'uniformity of approach may appeal to purists or academic commentators, (but) overlooks the need to accommodate local values, institutions and patterns of administration.' (pp. 9-10). This is the position we now take in comparing and contrasting international laws in this area.

\section{Results}


We now describe and analyse the supported and substitute decision-making in the four chosen jurisdictions in the context of five areas: The legal framework for supported and substitute decision- making; The criteria for intervention; The assessment process; Safeguards; Issues in practice

\subsection{Ontario, Canada}

The legal framework for supported and substitute decision-making

Canada signed the CRPD in 2007 and ratified it in 2010 with a reservation that its understanding of Article 12 was that it did allow substitute as well as supported decisionmaking. The legal framework for substitute decision-making in Ontario is provided through four provincial statutes which cover different aspects of decision-making for people who are assessed to be incapable of making the relevant decision: the Substitute Decisions Act 1992; Health Care Consent Act, 1996; Mental Health Act (most recently amended in 2000); and the Personal Health Information Protection Act 2004. D’Arcy Hiltz and Anita Szigeti in ‘A Guide to Consent and Capacity Law in Ontario'(2014), identify four types of decisions addressed by the legislation: decisions regarding 'property', 'treatment/placement', 'detention', and 'personal health information'. Hiltz and Szigeti (2014) state: “We are all presumed to have the capacity to manage our own property, to make our own decisions regarding treatment and disclosure of personal health information, and to live freely where we choose. Once we become sufficiently incapacitated that we or others are at serious risk of harm, the state owes us a duty to protect our interests and that of the community” (p.1).

In Ontario, the law and policy which requires support to be provided to enable the person to make the relevant decision tends to be underpinned through legal requirements around consent or broad policy positions on the importance of person-centred interventions, for example through the recovery approach. An example of the legal requirements on consent is described 
under the Health Care Consent Act (s.11(2)) where, for consent to be informed, the person should have received the information that "a reasonable person in the same circumstances would require in order to make a decision about the treatment”. Ontario's Mental Health and Addictions Strategy (Ministry of Health and Long-Term Care, 2011) outlines the broad policy

approach and specifies that all services should be based on the principles of: respect and understanding; healthy development, hope and recovery; person-directed services; and diversity, equity and social justice.

\section{The criteria for intervention}

Each of the four areas of decision making has unique criteria for intervention, assessment process, and safeguards. The test for capacity remains the same. For example, with respect to the management of property, findings of incapacity may be made under the $M H A$ or the Substitute Decisions Act. The MHA only applies to patients in a mental health facility. Under the MHA it is the responsibility of the attending physician to assess capacity to manage property. In all other circumstances capacity to manage property is assessed by a capacity assessor who may be a social worker or member of another regulated profession who has received additional training and certification. The test for capacity to manage property is found in the SDA 1992: “A person is incapable of managing property if the person is not able to understand information that is relevant to making a decision in the management of his or her property, or is not able to appreciate the reasonably foreseeable consequences of a decision or lack of decision” s.6, SDA. The Office of the Public Guardian and Trustee is the decision maker 'of last resort'. In the absence of a pre-existing power of attorney, the office of the Public Guardian and Trustee becomes the statutory guardian of the incapable person's property. 


\section{The assessment process}

For treatment decisions, it is the responsibility of the regulated health professional proposing the intervention to determine whether the person has the capacity to decide about the intervention but there is no specific assessment tool or recording format for this process. In Ontario there are more than twenty regulated health professions accountable to the public through their regulatory colleges. Social workers are not included as a regulated health profession, but psychologists are. Within institutional care, mental health law specifies that it is the responsibility of the physician providing treatment to assess the capacity of their patient. However, each regulated profession (including social work) is required by their College to assess capacity for informed consent if it rests with the patient. Otherwise, all treatment providers are required to use the identified substitute decision maker. Physicians may assume capacity unless they have reason to believe otherwise. A person admitted to a health care facility found to be without capacity to make treatment decisions is notified in writing via a Mental Health Act Form 33. The law also requires that a rights advisor is notified of this finding and that the person receive appropriate advice. The person may refuse rights advice.

Under the Substitute Decisions Act decisions about property, finances and personal care, specific guidance issued by the Capacity Assessment Office (2005) which states that it is the responsibility of the assessor to "to record, verify, organize and summarize the relevant information gathered from the person being assessed, as well as from family, professional caregivers or multi-disciplinary consultants and review of objective records. The assessor then evaluates this wealth of multi-dimensional information within the appropriate legal framework to arrive at an opinion about mental capacity” (p. III.1). Capacity assessors are members of regulatory colleges (including social workers) who have completed an assessed two day 
training course, then maintain their practice (conducting at least five assessments every two years).

\section{Safeguards}

Under the Substitute Decisions Act a person being assessed in the community must consent to the assessment, and also pay for the assessment. A court may order an assessment if there is sufficient concern about the person's capacity. People admitted to health care facilities are not required to consent to an assessment of their capacity, but they are required to receive rights advice following a finding of incapacity. Right advice is usually provided by the PPAO (Psychiatric Patient Advocate Office). The PPAO offers instructed and non-instructed advocacy services. It is also possible for the person to appeal against the assessment to an independent tribunal, the Consent and Capacity Board. It should also be noted that the law provides directions to substitute decision makers- decisions are to be made based first on any known prior capable wishes, and second, in the best interests of the incapable person.

\section{Issues in practice}

Consent and capacity is a very complex area of law in Ontario. The legal framework that ensures individuals receive the treatment they require is, generally, based on an institutional model of care. As a result there can be additional challenges for services attempting to engage and work with people who lack capacity to make treatment decisions and reside in the community. For example, the criteria for CTOs include that, in the previous three years, the person has either had two or more admissions to hospital or accumulated 30 or more days of in-patient care. This may not sufficiently reflect a more community orientated model of care and, in practice, most CTOs are initiated from inpatient units (O'Brien \& Farrell, 2005). Implied consent is permissible under the Personal Health Information Protection Act (PHIPA) in order 
to permit health information to be transferred between health care providers. Is it ethical to rely on implied consent if the person is receiving treatment involuntarily? With a wide range of possible assessors and processes under different laws and oversight processes it is also difficult to determine how consistently assessments are conducted across areas of practice and decisions.

\subsection{Victoria, Australia}

The legal framework for supported and substitute decision-making Australia signed the CRPD in 2007 and ratified it in 2008. As with Canada, the Government entered a declaration which interpreted the Convention to allow for substituted decisionmaking and 'compulsory treatment of persons... with mental disability'. Hence, the Victorian Government has proposed the introduction of supported decision-making on a spectrum with substituted decision-making in guardianship and mental health legislation, both of which have been subjected to major review activity in the last five years. Indeed, as of the 1 July 2014, the Mental Health Act 2014 (Vic) has entered into force. While this overview will principally focus on mental health legislation in Victoria, guardianship law reform also warrants brief attention as many people with mental illness are subject to financial administration orders and/or guardianship orders under this legislation. Australian courts have not engaged with the CRPD Committee's calls for the 'replacement of substituted decision-making regimes with supported decision-making', including the repeal of mental health legislation, an issue which remains the subject of ongoing debate in Australia and elsewhere.

Victoria has had separate substituted decision-making laws relating to adult guardianship (the Guardianship and Administration Act 1986) and involuntary treatment and detention (Mental Health Act 1986) for almost three decades. These two Acts formed part of legislation 
introduced in Victoria in the mid-1980s. This legislation, which was viewed as progressive at the time, has been reviewed through a new wave of reform. Recent moves to apply supported decision-making in the mental health context in Victoria reflect global efforts to minimise restrictive intervention, and to reduce the use of compulsory, non-consensual treatment. A number of key drivers have precipitated this trend, particularly: the advent of the CRPD and the impact of Victoria's Charter of Human Rights and Responsibilities Act 2006, the shift to an emphasis on a recovery approach in mental health policy and practice (Department of Health, 2011) and concerns about high rates of coercive psychiatric intervention in Victoria (Light, Kerridge, Ryan \& Robertson, 2012a and b).

The most recent mental health law reform proposals suggest that the Mental Health Act 2014, will promote supported decision-making and recovery principles through features including: the presumption of decision-making capacity; improved access to advocacy; advance statements; nominated persons; and formal recognition of the role of carers. There is on-going debate as to whether a rebuttable presumption of capacity is compliant with Article 12 of the CRPD (Morrisey, 2012), and the CRPD Committee - who, again, call for the abandonment of assessments of mental capacity altogether - clearly interpret that it is not.

The Guardianship and Administration Act 1986 (Vic) (Vic Guardianship Act) provides a substituted decision-making arrangement, with safeguards, for people with impaired decisionmaking due to disability. Three disability groups are typically subject to the Vic Guardianship Act: people with intellectual disabilities, people with cognitive disability (such as dementia and acquired brain injury), and those with psychosocial/ mental health disability. Two other statutes also provide for substitute decision-making mechanisms and guardianship provisions in Victoria: the Instruments Act 1958 (Vic) and the Medical Treatment Act 1988 (Vic). The only option for supporting people with impaired decision-making under these laws is to appoint a 
substitute decision-maker. Six broad appointments for limited substituted decision-making are available: guardians, administrators, the 'person responsible', attorneys, agents and enduring guardians. Victorian guardianship law does not currently provide any formal avenue for supported decision-making. However, a comprehensive report by the Victorian Law Reform Commission (VLRC) (2012), which drew broadly on Canadian adult guardianship law (Carney \& Beaupert, 2013), includes two major recommendations to introduce statutory supported decision-making mechanisms into current guardianship law: 'supporters' and 'co-decisionmaking'.

The VLRC proposed greater 'overlap’ between mental health and guardianship laws. Their major recommendation was to authorise for enduring personal guardians to make psychiatric treatment decisions over and above psychiatrists under the Mental Health Act 1986, if a person was deemed an involuntary patient due to considerations for their own wellbeing but not for reasons of public safety. The VLRC emphasised that guardianship powers should only be used for the benefit of the represented person and not for the protection of the public. Such powers would mean people with psychosocial disability could potentially appoint (or have appointed) a proxy, instead of having the 'clinical guardianship' granted to a psychiatrist by default. This measure is similar in nature to 'advance statements' (where healthcare or other decisions are set out in advance, to guide decisions at a future stage at which decision-making ability is compromised) and 'nominated persons' (where a preferred informal supporter is given a formal status to assist with healthcare and other decision-making).

Where substitute decision-making measures are taken, the VLRC proposed the replacement of the 'best interests' approach with a 'substituted judgment approach' (though there were some exceptions to this, such as where financial decisions were concerned). The 'best interests' 
standard was criticised for being too vague and often used as a euphemism for overriding the will of the individual. 'Substituted judgment' refers to representatives making a judgment based on the perceived wishes of the person with the impairment.

\section{The criteria for intervention}

Under the Mental Health Act 2014 (Vic) the Tribunal must make a Treatment Order if it is satisfied that the treatment criteria in s. 5 apply to the person, namely:

(a) the person has mental illness; and

(b) because the person has mental illness, the person needs immediate treatment to prevent -

(i) serious deterioration in the person's mental or physical health; or

(ii) serious harm to the person or to another person; and

(c) the immediate treatment will be provided to the person if the person is subject to a Temporary Treatment Order or a Treatment Order; and

(d) there is no less restrictive means reasonably available to enable the person to receive the immediate treatment.

Section 22 of the Vic Guardianship Act sets out the criteria by which the specialised tribunal decides upon guardianship appointments:

(1) If the Tribunal is satisfied that the person in respect of whom an application for an order appointing a guardian is made-

(a) is a person with a disability; and

(b) is unable by reason of the disability to make reasonable judgments in respect of all or any of the matters relating to her or his person or circumstances; and 
(c) is in need of a guardian — the Tribunal may make an order appointing a plenary guardian or a limited guardian in respect of that person.

\section{The assessment process}

The Mental Health Act 2014 (Vic) enables mental health practitioners and psychiatrists to initially order treatment in the context of assessment and temporary treatment orders if they are satisfied that the criteria for compulsory intervention, as set out above, are met.

The Vic Guardianship Act uses a functional approach to assessing capacity (even as the lack of 'reasonable judgment' must arise due to disability), and was one of the first adult capacity statutes in the world to discard explicitly status-based, disability-specific assessment. Nonetheless, the Act continues to draw a sharp distinction between those who have capacity and those who do not. This may change in the light of recent reform activity, which would bring assessment processes for statutory supported decision-making closer to that of Ontario described above.

\section{Safeguards}

The new Mental Health Act 2014 (Vic) seeks to embed a supported decision making model in order to enable compulsory patients to be involved in decision-making to the greatest extent possible and have their views and preferences respected. The key mechanisms that have been introduced to support recovery and enable supported-decision making include the presumption of capacity; a nominated persons scheme; the ability of patients to prepare advance statements that provide information about their treatment preferences and the introduction of a strengthened second psychiatric opinions scheme and improved access to advocacy. 
As noted previously, the Mental Health Act 2014 (Vic) has made some important changes that mean that mental health practitioners and psychiatrists can initially order treatment in the context of assessment and temporary treatment orders, but the new Mental Health Tribunal (formerly the Mental Health Review Board) now has primary decision powers in relation to extended orders. The Tribunal, in the context of a staged order scheme, has become the primary decision-maker for orders extending beyond 28 days. This represents an improved safeguard for those subject to orders because the Tribunal is now required to interpret a more specific and 'tightened' involuntary admission criteria, to base their decision on evidence presented by treating teams and the Tribunal has discretion regarding the length and location of the order (inpatient or community). Also the Act requires that decision making by psychiatrists and the Tribunal must take into account the person's views and preferences about treatment of his or her mental illness and the reasons for those views and preferences, including any recovery outcomes that he person would like to achieve. This includes taking into account people's advance statement, if they have prepared one, and the views of their nominated person, if they have one. The Mental Health Act 2014 (Vic) also supports the involvement of carers and guardians (section.5.2).

The Mental Health Act 2014 (Vic) provides guidance in relation to how to assess capacity to give informed consent and stresses the importance of people being treated as least restrictively as possible. In assessing capacity to give informed consent under the Mental Health Act 2014 (Vic) (Sec 68 (1)), it is emphasised that just because a person is an involuntary or compulsory patient that does not mean that they lack capacity to give informed consent and that any assessment needs to be specific to the decision at hand (sec 68 (2)) 
The Vic Guardianship Act was developed to encourage the appointment of family members rather than state officials as substitute decision-makers, with a strong emphasis on limited and reviewable orders (Carney \& Tait, 1997). While relatives or friends are often appointed to assist a person to make 'lifestyle' decisions, administrators (or financial managers) can be appointed to assist with financial decisions. As a last resort, public officials may be appointed as a guardian or administrator. In practice, it is often the person themselves (and not the tribunal) who appoints the substitute decision-maker, doing so at a time when they have capacity when predicting a future date in which they may be incapable of making certain decisions. Guardianship laws contain relatively few mechanisms for reviewing individual decisions by guardians. Instead, review measures centre on applying to the tribunal for a rehearing of the original guardianship order (Guardianship and Administration Act 1986 (Vic) s 60A).

A further safeguard is the Victorian Charter of Human Rights and Responsibilities Act 2006. The charter has been used to ensure that a stronger regard to is made to the human rights implications of guardianship and administration orders (Chesterman, 2013).

\section{Issues in practice}

Moving to a supported decision-making (SDM) approach presents particular challenges in Victoria. There are currently high levels of involuntary treatment - best represented by an estimate of 98 per 100,000 people subjected to CTOs (much higher than any other Australian state) (Light, Kerridge, Ryan \& Robertson, 2012a). This phenomenon is partly explained by the service system (minimal use of inpatient beds) and a range of practice issues. On the one hand CTOs are strongly supported by service providers who tend to be convinced about their effectiveness but they are also viewed to be driven by a service delivery culture that has adapted to using and relying upon forms of involuntary treatment. The move to a recovery-oriented 
service system has tended to be 'silent' about how this will relate to people on involuntary orders (Light, Kerridge, Ryan \& Robertson, 2012b). A highly respected service user advocate, Mary O’Hagan (2011), has suggested that legal coercion is “the elephant in the recovery room”. O’Hagan suggests that the four cornerstones of a recovery approach are hope and belief in people's potential, self-determination over their lives, the choice of a broad range of services, and equal participation in their communities. She argues that legal coercion erodes all the cornerstones of the recovery philosophy, yet it remains a core response in mental health systems. So, Victorian mental health service providers have a challenge ahead. The move to a Tribunal with extended powers and greater restriction on the ease to which involuntary orders can be made and justified will require new skills of assessment and innovation in service delivery. It will also be important to monitor and support the uptake of mechanisms introduced to encourage SDM and a recovery oriented approach, in particular Advance Statements and having access to a Nominated Person. In other jurisdictions this has been found to not be straightforward and may depend on ensuring that those who use these mechanisms have confidence that they will be influential and respected (Shields, Pathare, van der Ham \& Bunders, 2013). The Act enables 'overriding' of Advance Statements by the authorised psychiatrist and Nominated Persons have no specific powers under the Act so much of the value of these mechanisms will be determined by how they are embedded into practice. It has been suggested that, alongside law reform, reducing coercion may be supported through a variety of evidence-based strategies. Engagement and adherence has been found to be enhanced through enabling increased opportunities for choice (Davidson, Roe, Stern, Zisman-Ilani, O'Connell \& Corrigan, 2012), an approach that may be supported by the recently announced National Disability Insurance Scheme, which provides a self-directed funding approach for people with disabilities, including people with mental with disability in Australia, including psychosocial disability. Peer support has also been found to improve engagement with services 
(Jewell, Davidson \& Rowe, 2006; Davidson et al., 2012) but this requires significant organisational support. Finally, the Victorian Office of the Public Advocate has initiated a pilot supported decision-making program that will begin in 2014, which is specifically targeted at providing support to highly isolated individuals (Victorian Law Foundation, 2013). Developing models to operationalise supported decision-making is an important challenge for practice in Victoria at a time of law reform.

\subsection{England and Wales}

The legal framework for supported and substitute decision-making

In England the legal framework for supported and substitute decision-making is determined by two pieces of legislation: the Mental Capacity Act 2005 (MCA) and Mental Health Act 1983/2007 (MHA). The MCA is underpinned by five principles that can be summarised as follows: (i) That capacity should always be presumed; (ii) the optimisation of the person's ability to make decisions; (iii) that patients are entitled to make 'unwise decisions'; (iv) decisions and actions made for people must be in their best interests; (v) and that such decisions must be least restrictive in terms of rights and freedoms. The exact wording of the second principle is that "A person is not to be treated as unable to make a decision unless all practicable steps to help him to do so have been taken without success” (Section 1(3)). Although this commitment to supporting decision-making is appears to be positive, in practice substitute decision continues to be the main type of intervention when the MCA is used (Brown, Barber \& Martin, 2009).

The introduction of the MCA was particularly influenced by the requirement to 'close the Bournewood gap’ (Allen, 2010) which highlighted the longstanding problem of de facto detention. This arises when people do not have the capacity to consent to care, and would be 
prevented from leaving the care setting, are not held under any formal legal powers and the associated safeguards. Deprivation of Liberty Safeguards (DoLS) introduced by the MCA are designed to deal with this gap in the legal framework. The MCA also introduced the concept of the Lasting Powers of Attorney which enables the Attorney to make decisions about either personal welfare and/or property affairs. Processes associated with property and lasting power of attorney agreements can start before a person has lost capacity, but personal welfare ones cannot. A similar process is available to the Court of Protection through the appointment of a Deputy. The Deputy is likely to be a family member or perhaps a director of social services. The Deputy can consent on the person's behalf but can never consent to decisions that will shorten the person's life. Sections 24-26 of the MCA defines the concept of Advance Decisions and describes that processes which enable persons to refuse future specified treatment, but not other acts. Provided advance decisions are made when the person had capacity, and they are sufficiently specific to cover the patient's current predicament, clinicians must respect them. They can be made verbally and can be reversed by the individual if they regain capacity. Advance decisions that refuse life sustaining treatments (such as ventilation) have to be written, signed, and witnessed to be valid. It is incumbent on clinicians to find out if an advance decision exists and assess whether it is valid. The interface between the MCA and MHA has created complexity to substitute decision-making processes which will be discussed below.

\section{The criteria for intervention}

MCA 2005 s. 3(1) states that "a person is unable to make a decision for himself if he is unable: (a) to understand the information relevant to the decision, (b) to retain that information, (c) to use or weigh that information as part of the process of making the decision, or (d) to communicate his decision (whether by talking, using sign language or any other means). Under the Mental Health Act 1983, the criteria for compulsory admission are the tradition 
combination of mental disorder and risk, so, for example Section 2 states that "an application for admission for assessment may be made in respect of a patient on the grounds that:(a) he is suffering from mental disorder of a nature or degree which warrants the detention of the patient in a hospital for assessment (or for assessment followed by medical treatment) for at least a limited period; and(b) he ought to be so detained in the interests of his own health or safety or with a view to the protection of other persons”. The 2007 amending Act introduced compulsory community powers, in Section 17A(5) which may be used if: treatment is appropriate, necessary for health, safety or the protection of others, it can be provided in the community and is available. So, in the mental health law, the capacity to decide about treatment in hospital or community settings is not included in the criteria for compulsion.

\section{The assessment process}

Under the MCA, assessing whether a person has capacity involves two stages. To lack capacity, the person must have an impairment of or disturbance in the functioning of the brain or mind which leads to an inability to understand, retain, use, or weigh information relevant to a decision or to communicate a choice. Although there is a both a diagnostic threshold and a component that is specific to a decision, capacity can be assessed only in relation to a specific decision; this is a functional rather than status approach to assessing capacity. Mindful of the sometimes fluctuating nature of capacity, the MCA requires that capacity should be considered for each specific decision. The process for DOLS is that where the Managing Authority believes that a person in a care home or hospital will be deprived of their liberty, they contact the Supervisory Body to establish if a deprivation of liberty is occurring. Up to six assessment tasks are then available, carried out by a range of professionals. Under the MHA compulsory intervention is based on an application by the person's nearest relative or an Approved Mental Health Professional and two medical recommendations. 


\section{Safeguards}

Section 2 of the MCA highlights the steps that must be taken to ensure the Best Interests of the person, including a consideration of whether they will have at some other time, capacity, an encouragement of the person to fully participate in the decision-making process, consideration of past and present interests, consider their beliefs and attitudes and to consult relevant professionals, carers and relatives.

Late in the parliamentary process a decision was made to create an Independent Mental Capacity Advocate Service. It consists of people employed by independent, voluntary sector organisations who provide support and representation to citizens who are subject to the MCA. Although their decisions are not binding, professionals are required to consider these when making decisions. The MCA Code of Practice describes how advocates can be instructed for care reviews or adult protection cases, but they must be instructed and then consulted when serious medical treatment is being proposed (such as ventilation, major surgery, chemotherapy, and discontinuation of artificial nutrition or hydration). They must also be involved when accommodation for more than 28 days in hospital or eight weeks in a care home is being arranged or changed. Finally, The MCA created the Court of Protection which attempts to resolve any disputes and appeals against decisions of the Court of Protection can also made, with permission, to the Court of Appeal. Under the MHA people can appeal to the Mental Health Review Tribunal and, if they are under compulsory powers for six months and have not appealed themselves then the Hospital Managers' have a duty to refer them.

\section{Issues in practice}


Given the complex nature of the MCA and its interface with the MHA, it is not surprising that many dilemmas face professionals when using these laws. As highlighted above, in their early, influential paper Dawson and Szmukler (2006) raised concerns that this split in laws may lead to potentially discriminating practices. Owen, David, Richardson, Szmukler, Hayward and Hotopf (2009) found that professional judgements about service users experiencing psychoses and manic episodes of bipolar disorders were most strongly associated with incapacity, and that insight was the best discriminator of capacity status in these disorders. At present it is debatable how much impact the MCA has had on the practice of mental health professionals when both laws coincide in these ways as the MHA tends to be used and still allows for the compulsory treatment of people who have the capacity to refuse it.

Where carers are sensitively involved in decision-making, positive relationships can be built between them and professionals (Manthorpe, Samsi \& Rapaport, 2009). Others (Rapaport, Manthorpe \& Stanley, 2009) suggest that a drift towards substitute decision-making might be shaped by risk averse rather than rights based approaches. A Welsh study (Lepping, Sambhi \& Williams-Jones, 2010) examined how agencies managed DOLS processes. No service users were found to have been deprived of their liberty, $8 \%$ lacked capacity to make either basic or complex decisions and another 5\% lacked capacity to make complex decisions. Documentation was good in mental health and community directorates, but there were gaps in documentation (not practice) in the medical and surgical directorates. Routine collection of data improved documentation regarding deprivation of liberty criteria. They concluded by suggesting a likelihood that senior nursing staff underestimate the number of patients who lack capacity.

Brown, Barber and Martin (2009) discuss a number of problems associated with advance decision-making, as summarised in the case of Re T (Adult: Refusal of Medical Treatment) 
[1992] 4 All ER 649, including the important issue of how far the decision-maker has to go to establish the existence and validity of the advance decision. Few studies have been carried out into the way IMCA services have functioned since the introduction of the MCA. Redley, Clare, Dunn, Platten and Holland (2011) surveyed stakeholders during the first year of the operation of IMCA services as applied to adult safeguarding contexts. Although there were generally positive views expressed about the benefits of the new services, it was apparent that there are inconsistencies in the way that individuals and organisations carried out assessments, some problems around service integration and unmet training needs.

\subsection{Northern Ireland}

The legal framework for supported and substitute decision-making

In Northern Ireland there is not yet a specific mental capacity law to facilitate substitute decision-making across health, welfare and financial decisions for people with mental health problems who are not able to make the relevant decisions. The current framework is provided by a number of overlapping areas of law and policy. For physical health, and most mental health, decisions, if the person is unable to make the relevant decision, substitute decisionmaking is allowed under common law which requires that decisions, by those intervening, must be made in a person's best interests. The Mental Health (Northern Ireland) Order 1986 (MHO) enables substitute decision-making about the assessment and treatment of mental health problems; some welfare decisions under Guardianship; and the management of property and financial affairs (through the Office of Care and Protection). Guardianship under this Order provides very limited powers and is not a global substitute decision-making framework. Under Article 22(1) the guardian can require the person to reside at a specific place; require them to attend specific places for treatment, occupation, education or training; and require the person 
to allow specific people access to where they are living. There is no sanction when here is lack of compliance in these situations.

Other relevant policy and guidance for substitute decision-making exists which tends to relate more to supporting people to make their own decisions and so avoid the need for substitute decision-making. The Code of Practice (Department of Health and Social Services, 1992) for the MHO states that 'even when consent is not legally required, every attempt should be made to explain what is proposed and to obtain the patient's agreement' (para.5.9). The Department of Health, Social Services and Public Safety (DHSSPS) (2003) also provided more a more general 'Guide to Consent for Examination, Treatment or Care'. The current mental health policy, the Bamford Action Plan 2012-2015 (DHSSPS, 2012) asserts that people with mental health problems should expect to be encouraged and supported 'to look after their own health' and 'be supported...in their life choices' (p. 15).

In Northern Ireland it is currently proposed to introduce a new comprehensive legal framework, the Mental Capacity (Health, Welfare and Finance) Bill, to require that all practicable steps are taken to support decision-making and then, if necessary, to enable substitute decision-making for everyone who is not able to make a specific decision including if this is because of mental health problems. It is therefore proposed that this new law would provide a framework for supported and substitute decision-making for everyone and so a separate, potentially discriminatory, mental health law would no longer be needed (Dawson \& Szmukler, 2006; Bamford Review of Mental Health and Learning Disability, 2007).

The criteria for intervention 
Substitute decision-making under the common law has to be based on a reasonable belief that the person doesn't have the ability to make the relevant decision and then the intervention must be in the person's best interests. Intervention under the MHO is based on judgements about mental disorder and risk rather than impaired decision-making ability and so, in specific circumstances, compulsory treatment can still be imposed on a person who has the capacity to refuse it. The criteria for compulsory admission to hospital are set out in Article 4(2) which specifies that "An application for assessment may be made in respect of a patient on the grounds that: (a) he is suffering from mental disorder of a nature or degree which warrants his detention in a hospital for assessment (or for assessment followed by medical treatment); and (b) failure to so detain him would create a substantial likelihood of serious physical harm to himself or to other persons”. The criteria for Guardianship are specified in Article 18(2) and are that: “(a) he is suffering from mental illness or severe mental handicap of a nature or degree which warrants his reception into guardianship under this Article; and (b) it is necessary in the interests of the welfare of the patient that he should be so received".

Under the proposed Mental Capacity (Health, Welfare and Finance) Bill, which is currently the subject of public consultation (Department of Health, Social Services and Public Safety and Department of Justice, 2014), it is proposed that substitute decision-making would only be allowed when it is established that the person is unable to make the specific decision despite efforts to support them to do so. The gateway criterion for all substitute decision-making would therefore be impaired decision-making ability.

The assessment process

Assessment and intervention under the common law can be carried out by anyone. Under the MHO compulsory intervention must be based on a medical recommendation and an application 
completed by the person's Nearest Relative or, more commonly, by an Approved Social Worker (ASW). Interestingly the person's Nearest Relative or an ASW can also apply for Guardianship but it must be accompanied by two medical recommendations and a recommendation by another ASW. Under the proposed Mental Capacity Bill the assessment process would depend on the level of proposed intervention. Routine interventions could be based on a reasonable belief that the person was unable to make the decision. More serious interventions would require a formal and recorded assessment by an appropriately trained person. Interventions that involved interventions with potentially long-term consequences and/or deprivation of liberty and/or resistance or objection would require assessment by a medical practitioner and an ASW.

\section{Safeguards}

For decisions under the common law, unresolved differences and disputes must be referred to the High Court. Under the MHO it is possible to appeal to a Mental Health Review Tribunal. The Mental Capacity Bill will provide a range of safeguards across the different levels of intervention. The principles of autonomy and best interests will apply to everyone, but for serious interventions a nominated person will be consulted and involved and for some serious interventions a second opinion, an independent advocate and an authorisation process will be required. It will also be possible for people, and their nominated persons, to appeal to a Capacity Tribunal.

\section{Issues in practice}

The absence of a comprehensive legal framework means that most substitute decisions about health, welfare and finance are taken informally without formal safeguards. There are unusual anomalies such as an assumption that people in psychiatric hospitals are viewed as being 
voluntary incapable. This only refers to their financial decision-making capacity under common law but in practice, across settings, people are still sometimes regarded as globally capable/incapable. The MHO allows the possibility of compulsory intervention with someone who has the capacity to decide about the intervention. It is also not clear how consistently and/or well the guidance on informing and supporting consent is being implemented.

\section{Discussion}

We agree with Carney’s (2012) assertion that these complex issues associated with supported and substituted decision making in mental health services cannot be understood without an analysis of the social, political and professional contexts within jurisdictions. We believe that in comparing these influences and variations across jurisdictions it may be able to shed some light on these crucial, but often nuanced decision-making processes. In beginning this discussion about the legal frameworks in the chosen jurisdictions it is possible to argue that all attempt to address the similar problems and opportunities in providing support for people to make their own decisions, and when that is not possible, for a substitute decision to be made. The criteria and powers are broadly similar but, in light of the developments in practice and the CRPD, there are some interesting contrasting positions to highlight.

These comparisons can be viewed in the light of ongoing philosophical and ethical debates about the relative importance of informed consent, autonomy, duty of care and protection of others reflected in these legal frameworks. The Health Care and Consent Act in Ontario provides the most comprehensive framework for considering and respecting autonomy because it applies across all aspects of health care and treatment. In the other jurisdictions however, the views of a person with the capacity to refuse treatment can still be contradicted by substitute decision makers if there are sufficient concerns about their mental health and the level of risk 
they present. It will be interesting to observe if the proposed Mental Capacity (Health, Welfare and Finance) Bill in Northern Ireland can provide a legal framework which would only allow compulsory intervention if the person was unable to make the relevant decision. This approach was considered in the reform processes in Victoria and England and Wales but a dual mental health/mental capacity approach was continued.

All the current mental health law and capacity/guardianship laws described above include some form of disability criterion. So, even when the emphasis is focused on whether the person can make the relevant decision, in other words the functional approach, the criteria still include that the person must have some form of disability, disorder or diagnosis. It is interesting to consider whether this initial disability criterion is necessary and/or what its purpose is. The debate around Article 12 of the CRPD could suggest that these criteria may be both unnecessary and discriminatory. On the other hand it might be argued that a functional approach without some form of disability criterion would extend compulsory powers into areas, such as alcohol and drug use, where it has not traditionally been applied, beyond emergency interventions. What seems clear, however, is that laws which rely solely on judgements about the evidence of mental disorder and risk, in other words, a disability criterion without any requirement to consider the person's functional ability to make a decision, are not compatible with even the most cautious interpretation of the CRPD. That most mental health laws, except those that contain or are under, a primary capacity gateway criterion, are incompatible with Article 12 would seem one of the most obvious and important implications of the CRPD in practice although this is not where most of the debate has tended to be.

The MCA in England and Wales included supported decision-making as one of its principles and the Victorian government has emphasised supported decision-making in its new legal 
framework but there is still uncertainty across the jurisdictions about what a commitment in the law means in practice. The MCA Code of Practice (Department for Constitutional Affairs, 2007) suggests supporting someone to make their own decision by taking all practicable steps to: provide relevant information; communicate in an appropriate way; make the person feel at ease; and support the person. As Browning and colleagues (2014) suggest, it may be useful to distinguish between formal support decision-making as part of a legal process and more 'decision-making assistance’ for people, yet both appear necessary to promote autonomy and to support people to exercise their legal capacity on an equal basis with others. As acknowledged in the introduction to this paper, the complexities of supported decision making, especially what works for whom, is an important and developing area of practice and research.

A central issue across the jurisdictions are the complexities of the legal frameworks. It could be argued that a number of laws using highly specialist language may be necessary to address the range and nature of the issues involved in mental health and mental capacity services. However, even if that is the case, it would seem especially important that laws in this area are clear and accessible. Part of this usage can certainly be explained in terms of how these legal frameworks have developed over time. This justification, however, is less convincing for the more recent reform processes and there would appear to be a central irony that laws intended to promote and protect autonomy are opaque and difficult for service users and carers to understand.

Although the range of procedural safeguards are similar across the jurisdictions there are clear differences in the processes leading to compulsory interventions, the authorisation and appeal processes, statutory advocacy services and the time frames involved. In light of international human rights standards, such as the United Nations Mental Illness Principles, the European 
Convention on Human Rights and the CRPD there would appear to be decreasing justification for these, albeit relatively minor, differences.

In practice, where there are both mental health and mental capacity laws, the power conferred on professionals by mental health legislation tends to dominate mental health practice. It is possible that many of the issues associated with the ways in which these laws are implemented in these contexts may not be effectively addressed by further reform of legislation, but perhaps by more appropriate use of the current laws and improved mental health services which could prevent the need for compulsion.

\section{Conclusions}

Developments in practice, law and the growing importance of the CRPD have provoked much interesting and progressive debate about the legal frameworks for supported and substitute decision-making. Whatever shape these frameworks take across jurisdictions there is an obvious need for them to be clear, coherent and accessible and this should be promoted through increased service user/consumer and carer involvement in reform processes. It is encouraging that across the jurisdictions that we have described and analysed there is increasing attention on how to support people to make their own decisions but this does not seemed to have moved far beyond the acceptance that this is a sound principle. The differences between the jurisdictions in terms of roles and responsibilities in assessment, and safeguards, are becoming harder to justify; it is also the case that international human rights standards could be more specific about what is required to ensure that such principles are realised. Although a driver for change to these laws has been the universal shifts from institutional to community based care, the laws described above raise many questions about the protection of rights and the use of coercion in community settings. New approaches which are more focused on compelling 
service providers, rather than the people they are designed to support, may facilitate the necessary change. Legal frameworks can provide an outline of what should be in place but they are insufficient without the necessary training, resources, monitoring and enforcement processes to ensure that citizens are receiving the appropriate levels of support, care and protection of rights. Finally, it would appear that the debate about the future of laws based on mental disorder and risk, rather than decision-making ability, will continue for some time yet. The progress and implementation of the proposed new framework for Northern Ireland, and reform endeavours in the field elsewhere, may help inform this debate. 


\section{References}

Allen, N. (2010). The Bournewood Gap (As Amended?), Medical Law Review, 18(1), 78-85

Bach, M. \& Kerzner, L. (2010). A New Paradigm for Protecting Autonomy and the Right to Legal Capacity. Toronto: Law Commission of Ontario.

Bamford Review of Mental Health and Learning Disability (2007). A Comprehensive Legislative Framework. Belfast: Bamford Review.

Brown, R., Barber, P. \& Martin, D. (2009). The Mental Health Capacity Act: A Guide for Practice. Exeter: Learning Matters.

Browning, M., Bigby, C. \& Douglas, J. (2014). Supported Decision Making: Understanding How its Conceptual Link to Legal Capacity is Influencing the Development of Practice, Research and Practice in Intellectual and Developmental Disabilities, DOI: $10.1080 / 23297018.2014 .902726$

Burns, T., Rugkåsa, J., Molodynski, A., Dawson, J., Yeeles, K., Vazquez-Montes, M., Voysey, M., Sinclair, J. \& Priebe, S. (2013). Community treatment orders for patients with psychosis (OCTET): a randomised controlled trial. Lancet, 381(9878), 1627-1633.

Campbell, J., Brophy, L., Healy, B. \& O’Brien, A. M. (2006). International perspectives on the use of community treatment orders: Implications for mental health social workers. British Journal of Social Work, 36, 1101-1118. 
Capacity Assessment Office (2005). Guidelines for Conducting Assessments of Capacity. Toronto: Ontario Ministry of the Attorney General.

Carney, T. (2014). Clarifying, Operationalising, and Evaluating Supported Decision Making Models, Research and Practice in Intellectual and Developmental Disabilities, 1:1, 46-50, DOI: 10.1080/23297018.2014.902727.

Carney, T. (2013). Participation and service access rights for people with intellectual disability: A role for law? Journal of Intellectual and Developmental Disability, 38(1): 59-69.

Carney, T. (2012) Guardianship, Citizenship, and Theorizing Substitute-Decision-Making Law, Legal Studies Research Paper, Sydney Law School, No. 12/25Fcarney.

Carney, T. \& Beaupert, F. (2013). Public and private bricolage - challenges balancing law, services and civil society in advancing 'CRPD' supported decision-making. University of New South Wales Law Journal, 36(1), 175-201.

Carney, T. \& Tait, D. (1997). The Adult Guardianship Experiment: Tribunals and Popular Justice. Sydney: The Federation Press.

Chartres, D. \& Brayley, J. (2010). Office of the Public Advocate South Australia: Submission to the Productivity Commission Inquiry into Disability Care and Support. Collinswood: Office of the Public Advocate. 
Chesterman, J. (2013). The Future of Adult Guardianship in Federal Australia. Australian Social Work, 66(1), 26-38.

Chesterman, J. (2010). Supported Decision-Making: Options for Legislative Recognition. Melbourne: Office of the Public Advocate.

Churchill, R., Owen, G., Singh, S. \& Hotopf, M. (2007). International experiences of using Community Treatment Orders. London: Institute of Psychiatry.

Committee on the Rights of Persons with Disabilities (2014). General comment No. 1 (2014) Article 12: Equal recognition before the law. Geneva: United Nations.

Davidson, G., Kelly, B., Macdonald, G., Rizzo, M., Lombard, L., Abogunrin, O., CliftMatthews, V. \& Martin, A. (in press) Supported decision making: a review of the international literature, International Journal of Law and Psychiatry.

Davidson, L., Bellamy, C., Guy, K., \& Miller, R. (2012). Peer support among persons with severe mental illnesses: a review of evidence and experience. World Psychiatry, 11(2), 123128.

Davidson, L., Roe, D., Stern, E., Zisman-Ilani, Y., O'Connell, M., \& Corrigan, P. (2012). If I choose it, am I more likely to use it? The role of choice in medication and service use. International Journal of Person Centred Medicine, 2(3), 577-592. 
Dawson, J. \& Szmukler, G. (2006). Fusion of mental health and incapacity legislation. British Journal of Psychiatry, 188, 504-509.

Department of Health (2011). Framework for recovery-oriented practice. Melbourne: Mental Health, Drugs and Regions Division, Victorian Government Department of Health.

Department of Health (2012). A new Mental Health Act for Victoria: Summary of proposed reforms. Melbourne: Mental Health, Drugs and Regions Division, Victorian Government Department of Health.

Department of Health and Social Services (1992). Mental Health (Northern Ireland) Order 1986 Code of Practice. Belfast: Department of Health and Social Services.

Department of Health, Social Services and Public Safety (2003). Guide to Consent for Examination, Treatment or Care. Belfast: Department of Health, Social Services and Public Safety.

Department of Health, Social Services and Public Safety (2012). Bamford Action Plan 20122015. Belfast: Department of Health, Social Services and Public Safety.

Department of Health, Social Services and Public Safety and Department of Justice (2014) Draft Mental Capacity Bill (NI): Consultation Document, Belfast: Department of Health, Social Services and Public Safety and Department of Justice. 
Fistein, E.C., Holland, A.J., Clare, I.C. \& Gunn, M.J. (2009). A comparison of mental health legislation from diverse Commonwealth jurisdictions. International Journal of Law and Psychiatry, 32 (3), 147-155

Gooding, P. (2012). Supported Decision-Making: A Rights-Based Disability Concept and its Implications for Mental Health Law. Psychiatry, Psychology and Law, DOI:10.1080/13218719.2012.711683.

Gray, J.E., McSherry, B.M., O’ Reilly, R.L. \& Weller, P.L. (2010). Australian and Canadian mental health Acts compared. Australian and New Zealand Journal of Psychiatry; 44, 11261131.

Hiltz, D’A. and Szigeti, A. (2013). A guide to Consent and Capacity Law in Ontario, Markham: LexisNexis.

Jewell, C., Davidson, L., \& Rowe, M. (2006). The Paradox of Engagement: How Political, Organizational, and Evaluative Demands Can Hinder Innovation in Community Mental Health Services. Social Service Review, 1-26.

Kelly, B.D. (2014). An end to psychiatric detention? Implications of the United Nations Convention on the Rights of Persons with Disabilities. British Journal of Psychiatry, 204, 174-5.

Kohn, N. A., Blumenthal, J. A., \& Campbell, A. T. (2012). Supported decision-making: A viable alternative to guardianship. Penn State Law Review, 117, 1111. 
Large, M.M., Ryan, C.J., Singh, S.P., Paton, M.B. \& Nielssen, O.B. (2011). The predictive value of risk categorization in schizophrenia. Harvard Review of Psychiatry; 19, 25-33.

Lepping P., Sambhi R.S. \& Williams-Jones K. (2010). Deprivation of liberty safeguards - How prepared are we? Journal of Medical Ethics, 36(3), 170-3

Light, E., Kerridge, I., Ryan, C., \& Robertson, M. (2012a). Community treatment orders in Australia: rates and patterns of use. Australasian Psychiatry, 20(6), 478-482.

Light, E. M., Kerridge, I. H., Ryan, C. J., \& Robertson, M. D. (2012b). Out of sight, out of mind: making involuntary community treatment visible in the mental health system. Medical Journal of Australia, 196(9), 591-593.

Manthorpe, J., Samsi, K \& Rapaport, J. (2012). When the profession becomes personal: dementia care practitioners as family caregivers. International Psychogeriatrics, 24(6), 90210.

McSherry, B. (2012). Legal capacity under the Convention on the Rights of Persons with Disabilities. Journal of Law and Medicine, 20(1), 22-7.

McSherry, B., \& Freckelton, I. (Eds.). (2013). Coercive Care: Rights, Law and Policy. Abingdon: Routledge. 
Ministry of Health and Long-Term Care (2011). Open Minds, Healthy Minds: Ontario's Comprehensive Mental Health and Addictions Strategy. Toronto: Ministry of Health and LongTerm Care.

Morrisey, F. (2012). The United Nations Convention on the Rights of Persons with Disabilities: A New Approach to Decision-Making in Mental Health Law. European Journal of Health Law, 19(5), 423-440.

O’Brien, A-M. \& Farrell, S.J. (2005). Community Treatment Orders: Profile of a Canadian Experience. Canadian Journal of Psychiatry, 50, 27-30.

O’Hagan, M. (2011). Legal Coercion: the Elephant in the Recovery Room. Online, viewed on $18^{\text {th }}$ January 2014 at http://www.scottishrecovery.net/Latest-news/legal-coercion-theelephant-in-the-recovery-room.html.

Owen, G. S. David, A. S. Richardson, G., Szmukler, G. Hayward, P. \& Hotopf, M. (2009). Mental capacity, diagnosis and insight in psychiatric in-patients: a cross-sectional study. Psychological Medicine, 39(8), 1389-98.

Power, A., Lord, J. and DeFranco, A. (2013). Active Citizenship and Disability: Implementing the Personalisation of Support, Cambridge, Cambridge University Press.

Rapaport, J., Manthorpe, J. \& Stanley, N. (2009). Mental Health and Mental Capacity Law: Some Mutual Concerns for Social Work Practice. Practice: Social Work in Action, 21(2), 91105. 
Re T (Adult: Refusal of Medical Treatment) [1992] 4 All ER 649.

Redley, M, Clare, I.C.H., Dunn, M.C., Platten, M. \& Holland, A.J. (2011). Introducing the Mental Capacity Advocate (IMCA) Service and the Reform of Adult Safeguarding Procedures. British Journal of Social Work, 41(6), 1058-1069.

Rugkåsa, J., \& Dawson, J. (2013). Community treatment orders: current evidence and the implications. The British Journal of Psychiatry, 203, 406-408.

Shields, L. S., Pathare, S., van der Ham, A. J., \& Bunders, J. (2013). A review of barriers to using psychiatric advance directives in clinical practice. Administration and Policy in Mental Health and Mental Health Services Research, 1-14.

Szasz, T.S. (1961) The Myth of Mental Illness, New York, Harper and Row.Szmukler, G. \& Rose, N. (2013). Risk Assessment in Mental Health Care: Values and Costs. Behavioral Sciences and the Law, published online in Wiley Online Library (wileyonlinelibrary.com) DOI: 10.1002/bsl.2046.

Szmukler, G., Daw, R., \& Callard, F. (2014). Mental health law and the UN Convention on the rights of persons with disabilities. International journal of law and psychiatry, 37(3), 245-252.

Then, S.-N. (2013). Evolution and innovation in guardianship laws: Assisted decision-making. Sydney Law Review, 35(1), 133-166. 
United Nations (2007). From Exclusion to Equality: Realizing the Rights of Persons with Disabilities: Handbook for Parliamentarians. Geneva: United Nations.

Victorian Law Reform Commission (2012). Guardianship: Final Report 24. Melbourne: Victorian Law Reform Commission.

Victorian Law Foundation (2013). To offer isolated people with intellectual disabilities support to make their own decisions by matching them with an appropriately trained volunteer. Online, viewed $\quad 20^{\text {th }} \quad$ August $2013 \quad$ at http://www.victorialawfoundation.org.au/component/content/article/27-grants/generalgrants/191-office-of-the-public-advocate. 


\begin{tabular}{|c|c|c|c|c|}
\hline $\begin{array}{l}\text { Summary } \\
\text { table }\end{array}$ & Ontario & Victoria & $\begin{array}{l}\text { England and } \\
\text { Wales }\end{array}$ & Northern Ireland \\
\hline $\begin{array}{l}\text { Legal } \\
\text { framework }\end{array}$ & $\begin{array}{l}\text { Substitute } \\
\text { Decisions Act } \\
\text { 1992; Health } \\
\text { Care Consent } \\
\text { Act, 1996; and } \\
\text { the Mental } \\
\text { Health Act (most } \\
\text { recently } \\
\text { amended in } \\
\text { 2000?). The } \\
\text { Health Care and } \\
\text { Consent Act and } \\
\text { Substitute } \\
\text { Decisions Act }\end{array}$ & $\begin{array}{l}\text { Guardianship and } \\
\text { Administration } \\
\text { Act } 1986 \text { (Vic), } \\
\text { Mental Health } \\
\text { Act 2014, the } \\
\text { Instruments Act } \\
\text { 1958 (Vic) and } \\
\text { the Medical } \\
\text { Treatment Act } \\
1988 \text { (Vic) }\end{array}$ & $\begin{array}{l}\text { Mental Capacity } \\
\text { Act } 2005 \text { and } \\
\text { Mental Health } \\
\text { Act } 1983 / 2007\end{array}$ & $\begin{array}{l}\text { Common law and } \\
\text { Mental Health } \\
\text { (Northern } \\
\text { Ireland) Order } \\
1986\end{array}$ \\
\hline $\begin{array}{l}\text { Criteria for } \\
\text { intervention }\end{array}$ & $\begin{array}{l}\text { To understand } \\
\text { the information } \\
\text { that is relevant to } \\
\text { making a } \\
\text { decision about } \\
\text { the treatment, } \\
\text { admission or } \\
\text { personal } \\
\text { assistance }\end{array}$ & $\begin{array}{l}\text { Mental Health } \\
\text { Act } 2014 \text { requires } \\
\text { four criteria be } \\
\text { met including that } \\
\text { the person has } \\
\text { mental illness and } \\
\text { it is required for } \\
\text { their health or } \\
\text { safety or for the }\end{array}$ & $\begin{array}{l}\text { For intervention } \\
\text { under the MCA } \\
\text { the person must } \\
\text { be unable to } \\
\text { understand, } \\
\text { retain, use or } \\
\text { weigh, or } \\
\text { communicate the } \\
\text { relevant }\end{array}$ & $\begin{array}{l}\text { A reasonable } \\
\text { belief that the } \\
\text { person doesn't } \\
\text { have the ability to } \\
\text { make the relevant } \\
\text { decision and then } \\
\text { the intervention } \\
\text { must be in the }\end{array}$ \\
\hline
\end{tabular}




\begin{tabular}{|c|c|c|c|c|}
\hline & $\begin{array}{l}\text { service, as the } \\
\text { case may be, and } \\
\text { able to } \\
\text { appreciate the } \\
\text { reasonably } \\
\text { foreseeable } \\
\text { consequences of } \\
\text { a decision or } \\
\text { lack of decision”, }\end{array}$ & $\begin{array}{l}\text { protection of } \\
\text { others. } \\
\text { For Guardianship } \\
\text { the person must } \\
\text { have a disability } \\
\text { and be unable to } \\
\text { make reasonable } \\
\text { judgments. }\end{array}$ & $\begin{array}{l}\text { For the MHA it's } \\
\text { the traditional } \\
\text { mental disorder } \\
\text { and risk criteria. }\end{array}$ & $\begin{array}{l}\text { Mental disorder } \\
\text { and risk. }\end{array}$ \\
\hline Assessment & $\begin{array}{l}\text { No assessment } \\
\text { tool to record, } \\
\text { verify, organize } \\
\text { and summarize } \\
\text { the relevant } \\
\text { information } \\
\text { gathered from } \\
\text { the person being } \\
\text { assessed, as well } \\
\text { as from family, } \\
\text { professional } \\
\text { care-givers or } \\
\text { multi- } \\
\text { disciplinary } \\
\text { review of }\end{array}$ & $\begin{array}{l}\text { Assessment Order } \\
\text { - may be } \\
\text { community or } \\
\text { inpatient } \\
\text { - registered } \\
\text { medical } \\
\text { practitioner or } \\
\text { mental health } \\
\text { practitioner must } \\
\text { examine person } \\
\text { before making } \\
\text { Assessment Order } \\
\text { (and not more } \\
\text { than } 24 \text { hours } \\
\text { have passed since } \\
\text { examination) }\end{array}$ & $\begin{array}{l}\text { A functional } \\
\text { rather than status } \\
\text { approach to } \\
\text { assessing } \\
\text { capacity. } \\
\text { Encouragement } \\
\text { of the person to } \\
\text { fully participate } \\
\text { in the decision- } \\
\text { making process, }\end{array}$ & $\begin{array}{l}\text { Assessment and } \\
\text { intervention } \\
\text { under the } \\
\text { common law can } \\
\text { be carried out by } \\
\text { anyone. Under } \\
\text { the Mental Health } \\
\text { (Northern } \\
\text { Ireland) Order } \\
\text { 1986 compulsory } \\
\text { intervention must } \\
\text { be based on a } \\
\text { medical } \\
\text { recommendation } \\
\text { and an application } \\
\text { completed by the }\end{array}$ \\
\hline
\end{tabular}




\begin{tabular}{|c|c|c|c|}
\hline $\begin{array}{l}\text { objective } \\
\text { records. }\end{array}$ & 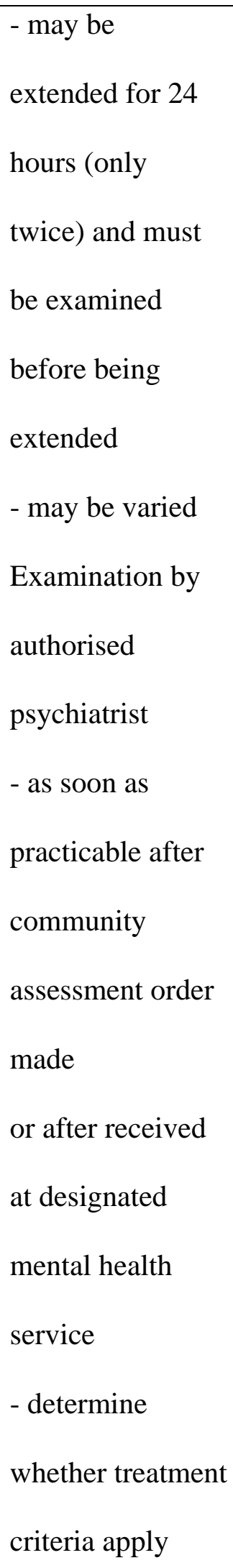 & $\begin{array}{l}\text { consideration of } \\
\text { past and present } \\
\text { interests, consider } \\
\text { their beliefs and } \\
\text { attitudes and to } \\
\text { consult relevant } \\
\text { professionals, } \\
\text { carers and } \\
\text { relatives. } \\
\text { Complexity of } \\
\text { DOLS }\end{array}$ & $\begin{array}{l}\text { person's Nearest } \\
\text { Relative or, more } \\
\text { commonly, by an } \\
\text { Approved Social } \\
\text { Worker. }\end{array}$ \\
\hline
\end{tabular}




\begin{tabular}{|c|c|c|c|c|}
\hline & & $\begin{array}{l}\text { - revoke } \\
\text { Assessment Order } \\
\text { or make } \\
\text { Temporary } \\
\text { Treatment Order } \\
\text { For Guardianship } \\
\text { there is a } \\
\text { functional } \\
\text { approach to } \\
\text { assessing capacity }\end{array}$ & & \\
\hline Safeguards & $\begin{array}{l}\text { Power of } \\
\text { attorney for } \\
\text { personal care or } \\
\text { 'Ulysses } \\
\text { Contract' } \\
\text { Consent and } \\
\text { Capacity Board } \\
\text { Advocacy } \\
\text { services }\end{array}$ & $\begin{array}{l}\text { Mental Health } \\
\text { Tribunal } \\
\text { Advance } \\
\text { Statements } \\
\text { Nominated } \\
\text { Persons } \\
\text { Victorian Civil } \\
\text { and } \\
\text { Administration } \\
\text { Tribunal (VCAT) } \\
\text { Advocacy } \\
\text { services }\end{array}$ & $\begin{array}{l}\text { MHRT } \\
\text { IMCAs } \\
\text { Best Interests } \\
\text { Assessors } \\
\text { DOLS } \\
\text { Lasting Power of } \\
\text { Attorney } \\
\text { Advance } \\
\text { decisions }\end{array}$ & $\begin{array}{l}\text { MHRT } \\
\text { Enduring Powers } \\
\text { of Attorney } \\
\text { Office of Care } \\
\text { and Protection, } \\
\text { High Court }\end{array}$ \\
\hline
\end{tabular}




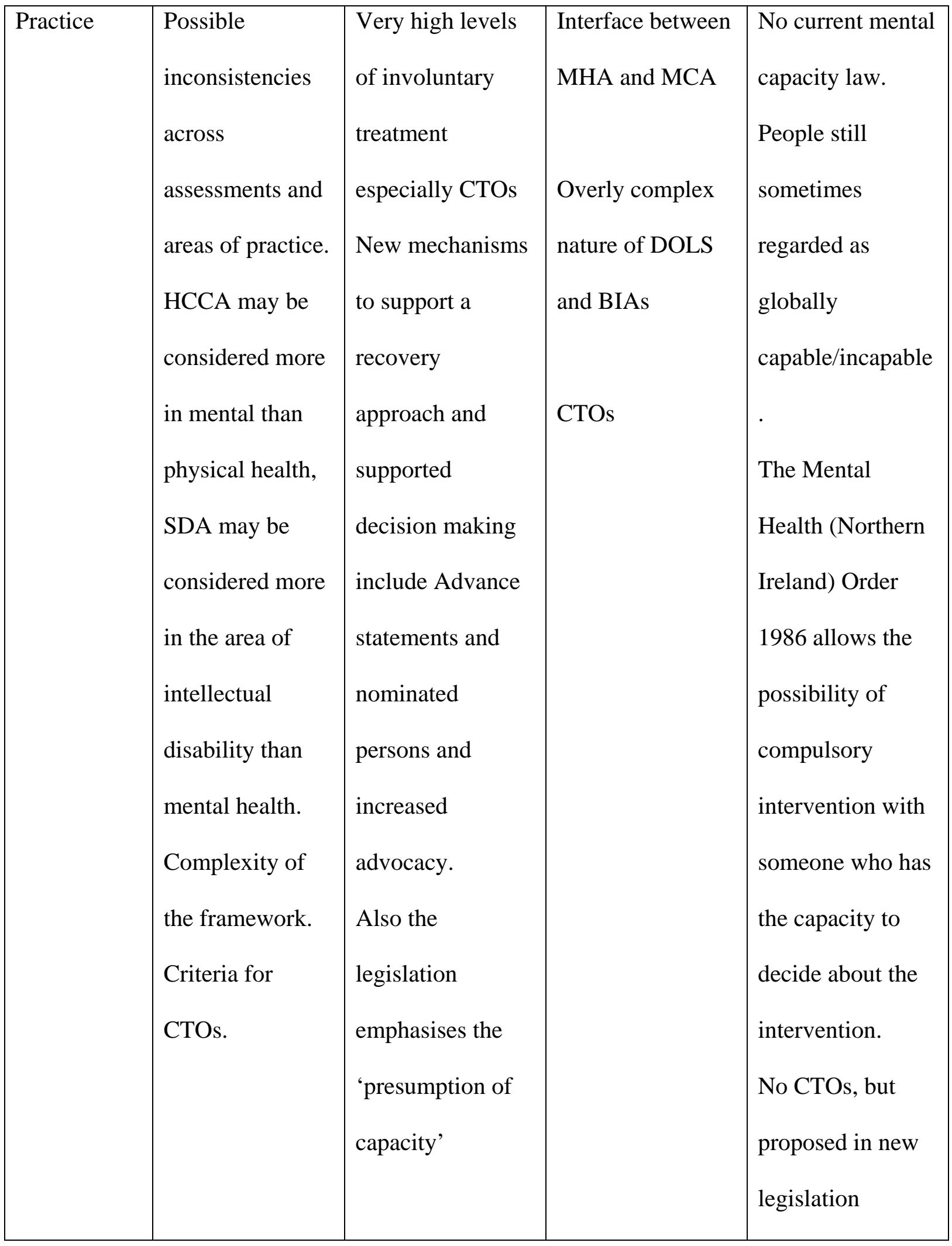

